\title{
Approaching End-of-Life with Aplomb and Plombage
}

\author{
Benjamin T. Galen, M.D.
}

Department of Internal Medicine, Division of Hospital Medicine, Albert Einstein College of Medicine and Montefiore Medical Center, Bronx, NY, USA.

KEY WORDS: plombage; tuberculosis; lung cancer; end-of-life.

J Gen Intern Med 32(2):227

DOI: $10.1007 / \mathrm{s} 11606-016-3828-6$

(C) Society of General Internal Medicine 2016

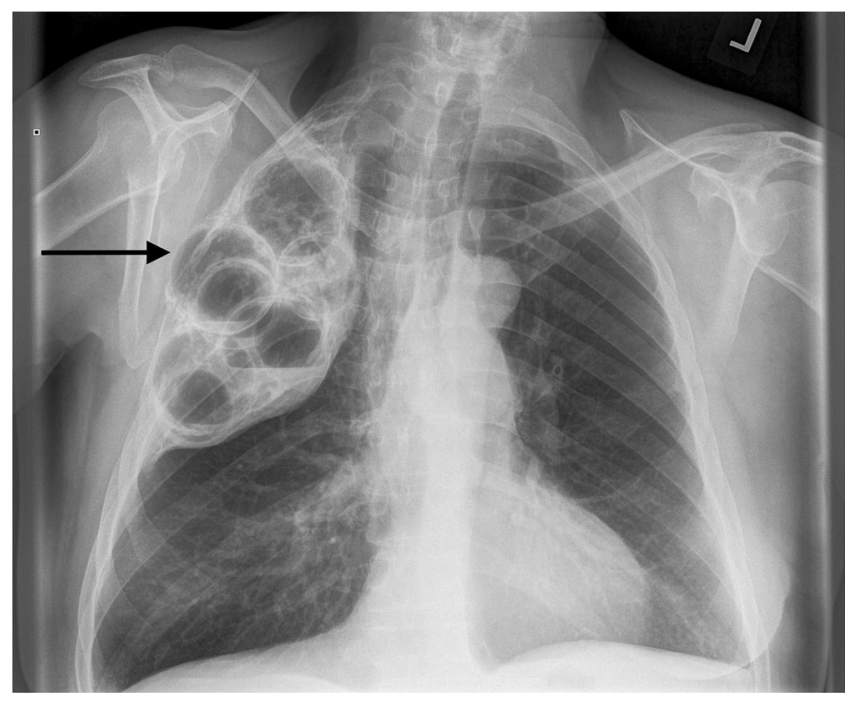

Figure 1. PA chest $x$-ray from 7 years prior with Lucite-ball plombage at black arrow.

A n 84-year-old gentleman was admitted with complications from lung adenocarcinoma. He had a remote history of pulmonary tuberculosis, and was status post plombage of the right upper thorax (Fig. 1). Based on the observation that patients with pulmonary tuberculosis were apparently cured after a spontaneous pneumothorax, methylmethacrylate (Lucite) balls were used in the early to midtwentieth century to collapse the infected lung, a practice known as Lucite-ball plombage. ${ }^{1}$ Late complications of plombage include infection, fistulization, ball fractures, cancer involving the balls, and even migration outside the thoracic cavity. ${ }^{2,3}$ Lucite-ball plombage was eventually deemed antiquated due to high complication rates and the advent of effective antituberculosis medications. This patient's anterior mediastinal adenocarcinoma had been diagnosed three years

Received June 8, 2016

Revised June 24, 2016

Accepted July 20, 2016

Published online August 3, 2016

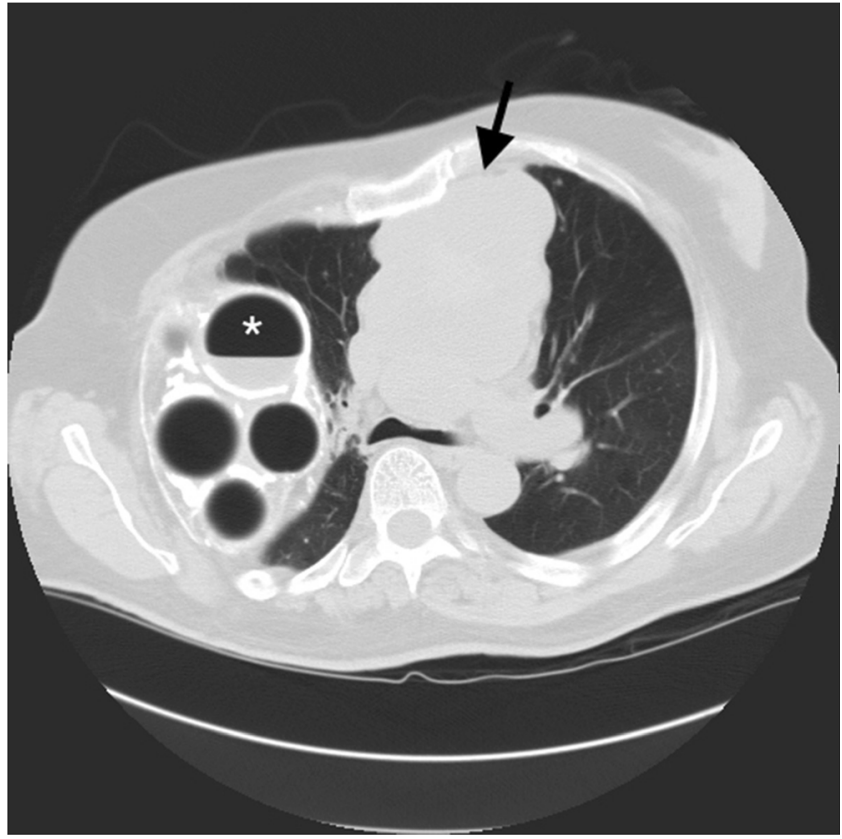

Figure 2. Chest computed tomography with large anterior mediastinal adenocarcinoma at black arrow. An air/fluid level is seen in one of the thoracic plombage balls (white asterisk).

prior without clear connection to the plombage cavity, deemed unresectable, and was treated with palliative chemotherapy and radiation (Fig. 2). The air/fluid level seen in one of the thoracic balls was unchanged for many years (Fig. 2, white asterisk). He died of sepsis after electing for comfort care.

Corresponding Author: Benjamin T. Galen, M.D.; Weiler Division, Department of Medicine, Montefiore Medical Center, Suite 2-76, 1825 Eastchester Road, Bronx, NY 10461, USA (e-mail: Bgalen@montefiore.org).

\section{Compliance with Ethical Standards:}

Conflict of Interest Statement: The authors declare that they do not have a conflict of interest.

\section{REFERENCES}

1. Garetier M, Rousset J. Thoracic Balls Can Med Assoc J. 2011;0:cmaj.110529v1-cmaj.110529. doi:10.1503/cmaj.110529.

2. Yadav S, Sharma $\mathbf{H}$, Iyer $\mathbf{A}$. Late extrusion of pulmonary plombage outside the thoracic cavity. Interact Cardiovasc Thorac Surg. 2010;10:808-10.

3. Gotoh S, Chohnabayashi N. Infection 57 years after plombage. NEJM. 2009;360:23. 